\title{
Alkali treated coir/pineapple leaf fibres reinforced PLA hybrid composites: Evaluation of mechanical, morphological, thermal and physical properties
}

\author{
R. Siakeng ${ }^{1}$, M. Jawaid ${ }^{2}$, M. Asim ${ }^{2}$, N. Saba ${ }^{2}$, M. R. Sanjay ${ }^{1}$, S. Siengchin ${ }^{1}$, H. Fouad ${ }^{3,4}$ \\ ${ }^{1}$ Department of Mechanical and Process Engineering, The Sirindhorn International Thai-German, Graduate School of \\ Engineering (TGGS), King Mongkut's University of Technology North Bangkok, 10800 Bangkok, Thailand \\ ${ }^{2}$ Institute of Tropical Forestry and Forest Products (INTROP), Universiti Putra Malaysia, 43400 UPM Serdang, Selangor, \\ Malaysia \\ ${ }^{3}$ Applied Medical Science Department, Community College, King Saud University, P.O. Box 10219, 11433 Riyadh, \\ Saudi Arabia \\ ${ }^{4}$ Biomedical Engineering Department, Faculty of Engineering, Helwan University, P.O. Box 11792, Helwan, Egypt
}

Received 6 November 2019; accepted in revised form 9 January 2020

\begin{abstract}
The present study deals with the incorporation of different ratios of alkali-treated coir fibres (CF) and pineapple leaf fibres (PALF) in polylactic acid (PLA) hybrid composites. Developed hybrid composites are characterized in terms of mechanical, morphological, thermal and physical properties. Mechanical characterization revealed that alkali-treated C3P7 hybrid composites (CF:PALF = 3:7) showed highest tensile strength (30.29 MPa) and young's modulus (5.16 GPa) among all hybrids composites, whereas C1P1 (CF:PALF = 1:1) showed highest impact properties. Scanning electron microscopy (SEM) justified the consequence of alkali treatment on fibre-matrix adhesion. Thermal analysis revealed that C1P1 and C7P3 (CF:PALF = 7:3) having a higher thermal stability and char content due to the higher content of lignin in CF. Remarkably, the coefficient of thermal expansion (CTE) of treated hybrid composites displayed lesser values than untreated hybrid composites. The physical tests revealed that C3P7 showed highest water absorption (WA) and thickness swelling (TS) though after treatment the $W A$ and $T S$ values get reduced. Overall results indicated that treated CF/PALF/PLA hybrid composites possess enhanced mechanical, thermal and physical properties with lowered CTE over untreated CF/PALF/PLA hybrid composites. The success of these findings results sustainable and degradable hybrid composites for different outdoor and food packaging-based applications.
\end{abstract}

Keywords: biopolymers, mechanical properties, thermal properties, natural fibres, thickness swelling

\section{Introduction}

Natural fibre plastic thermosets or thermoplastics composites are promising and sustainable green materials to achieve durability without the utilization of toxic chemicals [1]. Currently, the most commonly used agricultural by-products or agricultural-waste materials as reinforcement includes most of the cereal stalks, rice husks, bagasse, coconut fibres, corn cobs, nutshells and other wastes might alleviate the defined shortage [2]. Natural fibres such as coir fibres (CF) and pineapple leaf fibres (PALF) are interesting reinforcement in a composite system due to their specific properties such as low density, lightweight and non-abrasiveness during processing. In addition, they are low cost, renewable, biodegradable and abundantly available [3]. CF (Cocos nucifera) is known as versatile lignocellulosic fibres and is currently broadly being used in diverse indus- 
trial applications [4]. CF composed of a lower percentage of cellulosic content (36-43\%) and hemicellulose (15.17\%) and high level of lignin (32.25\%) as the bonding materials and very high microfibrillar angle $\left(30-45^{\circ}\right)$ in comparisons to other natural fibres $[5,6]$. Due to less cellulosic content, CF's exhibit lower tensile modulus and strength compared to other agro-fibres [4]. PALF's are major agricultural waste materials which are abundantly available in producer countries. They are renewable and degradable cheap materials for various industries as well as research purposes [7-9]. PALF is made up of high cellulosic content $(70-82 \%)$, lignin (5-12\%) and ash $(1.1 \%)[3,7]$.

Several pieces of research have been conducted using $\mathrm{CF}$ as filler or reinforcement in biocomposites owing to its good structural and wear properties [10]. Han et al. [11] studied thermal and flammability properties of PLA/CF composites and reported that plasma treatment enhanced the composites thermal stability, in addition, reducing shrinkage with the increase of the fibre content. Another research on CF reinforced polypropylene (PP) composites showed high strain failure along with better strain compatibility of fibre and matrix [12]. Rosa et al. [13] investigated various CF loading in ethylene-vinyl alcohol/glycerol/starch blends. They observed that tensile strength was decreased with increase in the fibre content; though tensile modulus improved considerably. Fibre content slightly affects the composite's thermal stability without disturbing its biodegradability. Another piece of research based on PALF reinforced PLA composites reported that tensile modulus and thermal stability get slightly improved with the addition of PALF [14]. Research on natural fibre reinforced composites are mainly conducted on single fibre and matrix which focuses on improving the physico-chemical qualities such as fibre-matrix bond strength, poor wettability, and improvement on dimensional stability [15-18] to substitute non-renewable synthetic fibre reinforced polymer composites.

PLA is one of the most popular commercial biopolymer derived from renewable resources like corn and sugarcane [19]. PLA based composites materials are appropriate for a variety of applications, though the thermal and mechanical properties of composites rely on the interfacial bonding of polymer and natural fibres [20]. CF and PALF are valuable natural fibres which are available in Malaysia abundantly as agricultural wastes which are potentially positive materials with respect to environmental concerns as well. Hybridization of fibres has advantages over a single fibre composite system as different fibres exhibit different properties which can complement each other [21, 22]. PALF will improve the tensile and flexural strength of the composites due to its anatomical structure [23] while CF will increase modulus and impact resistance properties. CF will help to improve the thermal properties due to its lignin content and will reduce water absorption and thickness swelling due to its lower cellulosic content [24] and also reduce the cost of the material. Hybridizing these two different fibres with PLA biopolymer has environmental and economic advantages. Dispersion and different fibre contents in hybrid composites is likely to improve the mechanical properties as compared to single fibre based polymer composite [25, 26]. Therefore, hybrid composites are cost-effective to develop good strength materials based on the properties of natural fibres [27].

Research findings reviewed that surface treatment of PALF and CF considerably enhanced the mechanical and thermal properties $[3,28]$. However, research on surface-treated CF and PALF reinforced PLA composites are still very inadequate and no details on hybrid CF/PALF/PLA composites have been found in the literature. Our previous research on mechanical, microstructural failure and thermal properties of PALF/CF/PLA hybrid composites were studied [3, 29] and found that CF and PALF loading in a 1:1 ratio improved the thermal and mechanical properties than pure PLA. Addition of CF also enhanced its impact and dynamic mechanical properties of the hybrid composites with regard to the pure PLA. A current research study is the extension of the previous study based on untreated CF/PALF/PLA hybrid composites [3]. From this study, we assumed that treated PALF will improve the mechanical properties such as tensile strength and flexural strength while $\mathrm{CF}$ will increase modulus and impact resistance properties. SEM helped in analyzing the behavior of treated and untreated fibres in the composites. CF will help to improve the thermal properties due to it lignin content and reduce water absorption and thickness swelling due to its lower cellulosic content.

\section{Experimental}

\subsection{Materials}

The PLA used in this research was Natureworks Ingeo $^{\mathrm{TM}}$ Biopolymer $6202 \mathrm{D}$ pellets supplied by TT 
Table 1. Properties of PLA biopolymer [30].

\begin{tabular}{|l|c|l|c|}
\hline \multicolumn{1}{|c|}{ Characteristics } & Description & \multicolumn{1}{c|}{ Characteristics } & Description \\
\hline Physical state & Pallets & Tensile strength & $14.68 \mathrm{MPa}$ \\
\hline Colour & Translucent white & Young's Modulus & $3.98 \mathrm{GPa}$ \\
\hline Odour & No odour & Flexural strength & $27.87 \mathrm{MPa}$ \\
\hline Density & $1.25 \mathrm{~g} / \mathrm{mol}$ & Flexural modulus & $3.75 \mathrm{GPa}$ \\
\hline Melting point & $150-170^{\circ} \mathrm{C}$ & Impact strength & $2.58 \%$ \\
\hline Glass transition temperature & $55-60^{\circ} \mathrm{C}$ & Water absorption & $1.42 \%$ \\
\hline Molecular weight & $74000 \mathrm{~g} / \mathrm{mol}$ & Thickness swelling & \\
\hline
\end{tabular}

Table 2. Properties of CF and PALF [30].

\begin{tabular}{|c|c|c|c|c|c|}
\hline Properties & $\mathbf{C F}$ & PALF & Properties & $\mathbf{C F}$ & PALF \\
\hline Density & 1.20 & 1.07 & Moisture absorption [\%] & 10 & 11.8 \\
\hline Diameter & $100-450$ & $20-80$ & Microfibrillar angle $\quad\left[^{\circ}\right]$ & $30-45$ & $8-15$ \\
\hline Cellulose & 42.14 & 81.27 & Elongation at break $[\%]$ & $17-47$ & $1.6-4$ \\
\hline Hemicelluloses [\%] & 15.17 & 12.31 & Aspect ratio & $20-100$ & $125-500$ \\
\hline \multirow[t]{2}{*}{ Lignin } & 35.25 & 3.46 & Tensile strength & $105-175$ & $413-1627$ \\
\hline & & & Youngs modulus & $4-6$ & $34.5-82.5$ \\
\hline
\end{tabular}

Biotechnologies Sdn. Bhd., Penang, Malaysia. The properties of PLA are shown in Table 1. CFs used in this research was supplied by Innovative Pultrusion Sdn Bhd. Seremban, Malaysia whereas PALF were procured from Southern part of India. Basic information regarding these fibre properties are displayed in Table 2. Sodium Hydroxide ( $\mathrm{NaOH}$ ) flakes used for fibre treatment were supplied by Evergreen Engineering \& Resources, Selangor, Malaysia.

\subsection{Treatment of fibres}

CF's and PALF were grounded in size $1 \mathrm{~mm}$ and immersed into alkaline solution $(6 \% \mathrm{NaOH})$ for $3 \mathrm{hrs}$. After immersion, these fibres were washed with tap water to attain neutral $\mathrm{pH}$. Then the fibres were airdried for $48 \mathrm{hrs}$. The selection of chemical, concentration and soaking time for surface treatment of $\mathrm{CF}$ and PALF were followed from our previous study [3].

\subsection{Preparation of samples}

PLA pellets and fibres were dried at $80^{\circ} \mathrm{C}$ for $24 \mathrm{~h}$ in the oven to make sure moisture is removed.
CF/PALF/PLA mixtures were prepared by using an internal mixer (Brabender) for $10 \mathrm{~min}$ at $180^{\circ} \mathrm{C}$ temperature and $50 \mathrm{rpm}$ speed. The fibre loading in PLA was constant at $30 \mathrm{wt} \%$ with different CF:PALF ratios (3:7, 1:1 and 7:3). Two different batches of each combination were prepared to verify reproducibility. The hybrid composites were compression moulded in a heated press at $180^{\circ} \mathrm{C}$ for about 10 minutes without pressure. After compression moulding, the samples were quenched using a water-cooled press and stored at room temperature before subsequent characterization. Developed hybrid composites were cut into different shapes and sizes according to the respective characterizations. The experimental density and composition of CF and PALF in PLA hybrid composites are shown in Table 3.

\section{Characterizations}

\subsection{Tensile test}

Tensile tests of hybrid composites were carried out using a $5 \mathrm{kN}$ Bluehill INSTRON Universal Testing Machine, as per ASTM standard D 638-14 (2014).

Table 3. Density and formulation of CF/PALF/PLA hybrid composites.

\begin{tabular}{|c|c|c|c|c|c|}
\hline \multirow{2}{*}{$\begin{array}{c}\text { Composition of hybrid composites } \\
\text { (70\% PLA constant) }\end{array}$} & PLA & $\mathbf{C F}$ & PALF & \multicolumn{2}{|c|}{$\begin{array}{c}\text { Density } \\
{\left[\mathrm{g} / \mathrm{m}^{3}\right]}\end{array}$} \\
\hline & \multicolumn{3}{|c|}{$\begin{array}{c}\text { Percentage by weight } \\
{[w t \%]}\end{array}$} & Untreated & Treated \\
\hline Pure PLA & 100 & - & - & \multicolumn{2}{|c|}{1.2} \\
\hline $30 \%(30 \% \mathrm{CF} / 70 \% \mathrm{PALF})(\mathrm{C} 3 \mathrm{P} 7)$ & 70 & 9 & 21 & 1.05 & 1.19 \\
\hline $30 \%(50 \% \mathrm{CF} / 50 \% \mathrm{PALF})(\mathrm{C} 1 \mathrm{P} 1)$ & 70 & 15 & 15 & 1.07 & 1.21 \\
\hline $30 \%(70 \% \mathrm{CF} / 30 \%$ PALF $)(\mathrm{C} 7 \mathrm{P} 3)$ & 70 & 21 & 9 & 1.09 & 1.18 \\
\hline
\end{tabular}


The temperature and humidity were set at $22{ }^{\circ} \mathrm{C}$ and $50 \%$ respectively. Six rectangular specimens were cut from each hybrid composites, and they were shaped into a dumbbell $\left(120 \times 20 / 13 \times 3 \mathrm{~mm}^{3}\right)$ by a plastic moulder machine. The crosshead speed for this test was set at $1.0 \mathrm{~mm} / \mathrm{min}$ and samples were gripped at a $30 \mathrm{~mm}$ gauge length.

\subsection{Scanning electron microscopy (SEM)}

The investigation on surface morphology and microstructure of untreated and treated tensile fractured samples were done by SEM. The samples were gold coated and operated at emission current of $58 \mu \mathrm{A}$, using a Hitachi S-3400N-SEM machine at $5.0 \mathrm{kV}$. The microscopic images also analyse the fibre distribution and pattern of fracture.

\subsection{Fourier transform infrared spectrometry (FTIR)}

FTIR study of both untreated and alkali-treated CF/PALF/PLA hybrid composites were carried out by using FTIR machine (SHIMADZU81001, Japan) to investigate the changes in functional groups on the fibre surfaces and to confirm the chemical interaction between PLA and fibres. All spectra were recorded in the range from 4000 to $500 \mathrm{~cm}^{-1}$.

\subsection{Izod notched impact test}

For impact properties characterization, $70 \times 15 \times$ $8 \mathrm{~mm}^{3}$ sizes samples of untreated and treated $\mathrm{CF} /$ PALF/PLA hybrid composites were analysed using impact testing machine (Instron CEAST 9050). The temperature and humidity were set at $22^{\circ} \mathrm{C}$ and $50 \%$. The dimensions and conditions of the tests were as per ASTM D256-10e1 (2010). The average impact load of all samples was calculated and demonstrated in the chart.

\subsection{Thermogravimetric analysis (TGA)}

Thermal properties of both untreated and alkalitreated CF/PALF/PLA hybrid composites were characterized by using TG machine (TGA Q 500 TA Instrument, USA) according to ASTM E1131-08. Tests were carried out from room temperature 30 to $600^{\circ} \mathrm{C}$ at $20^{\circ} \mathrm{C} /$ minutes heating rate.

\subsection{Thermomechanical analysis (TMA)}

Thermomechanical analysis calculated the composite's Coefficient of Thermal Expansion (CTE). The dimensions of samples were $5 \times 5 \times 3 \mathrm{~mm}^{3}$ according to ASTM D696-16. Thermomechanical analyzerQ400 (TA Instruments) was utilized for this test. The temperature was set at 30 to $200^{\circ} \mathrm{C}$ withat the rate of $5^{\circ} \mathrm{C} / \mathrm{min}$. the objective of this test to dimension changes in the sample thickness to analyse the CTE of the composite.

\subsection{Water absorption $(W A)$ test}

To investigate water absorption ( $W A$ ) of the composites, samples were immersed in distilled water. The weights of all the samples were carefully noted down before and after soaking. WA was examined at three intervals such as $3^{\text {rd }}, 5^{\text {th }}$ and $7^{\text {th }}$ (saturation) day from the day of soaking. The samples were wiped dry thoroughly before taking a measurement for accuracy in measurement. The $W A$ was calculated by taking an average of all the measurements value. $W A \%$ was calculated via Equation (1). The test was conducted using ASTM D570-98 standard for different periods of time:

$W A[\%]=\frac{W_{\mathrm{n}}-W_{\mathrm{d}}}{W_{\mathrm{d}}} \cdot 100$

where $W_{\mathrm{d}}$ and $W_{\mathrm{n}}$ are the weight of samples before and after immersion respectively.

\subsection{Thickness swelling (TS) test}

$T S$ tests were carried out on six specimens of each sample of treated and untreated CF/PALF/PLA hybrid composites by calculating dimensions of each sample. TS was investigated according to ASTM D570-98 (1998) by using Equation (2). The dimensional measurement of the composites was measured three times, $3^{\text {rd }}, 5^{\text {th }}$ and $7^{\text {th }}$ days from immersion dates and samples were also measured before immersing into water.

$\operatorname{TS}[\%]=\frac{T_{1}-T_{0}}{T_{0}} \cdot 100$

where $T_{0}$ and $T_{1}$ are the thickness before and after soaking.

\section{Results and discussion}

\subsection{Tensile properties}

The tensile modulus and strengths of the various ratio of fibre loaded untreated and alkali-treated hybrid composites are shown in Figure 1. Among untreated hybrid composites, C3P7 showed least tensile strength and modulus whereas C1P1 showed highest. C7P3 showed better tensile strength and 


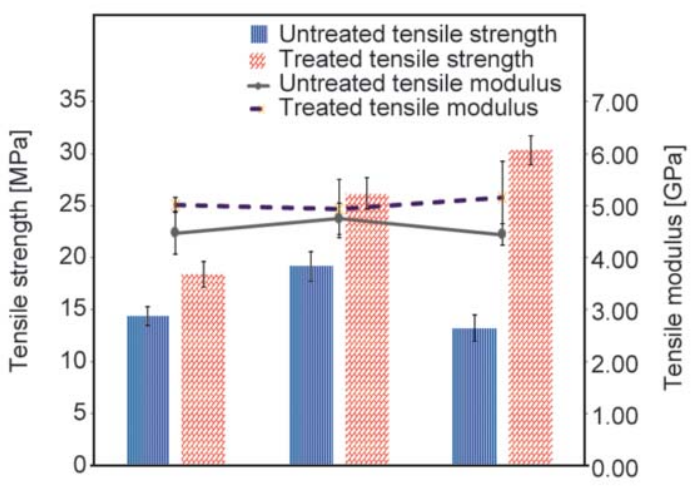

Figure 1. Tensile properties of untreated and treated CF/PALF/PLA hybrid composites.

modulus than C3P7 but improvement is not significant. After treatment of the fibres, the tensile strength improved with an increase in the proportion of PALF in the composites. Treated C7P3 exhibited $18.41 \mathrm{MPa}$ tensile strength which was $128.11 \%$ higher than untreated C7P3. The tensile modulus of treated C7P3 showed $5.02 \mathrm{GPa}$ that was $112.3 \%$ higher than untreated C7P3.

Treated C1P1 showed higher tensile strength (26.15 MPa) and modulus (4.94 GPa) than the untreated counterpart by 136.55 and $104 \%$ respectively. It is evident that untreated PALF and CF reduced the tensile strength and modulus due to poor interfacial bonding of fibres and PLA due to the presence of impurities and hydroxyl groups on the fibres [31]. It is reported that treated PALF enhanced tensile strength and modulus drastically by debonding the fibres bundles to improve the effectiveness of surface area during contact with the matrix [32].

A previous study [30] showed that tensile properties of neat PLA and Coir/PLA and PALF/PLA composite and found out that tensile strength and modulus of neat PLA are 14.68 MPa and 3.98 GPa respective1y. Coir/PLA composites showed tensile strength (13.96 MPa) lower and tensile modulus (4.35 MPa) higher than neat PLA, while PALF/PLA composites showed both tensile strength $(21.86 \mathrm{MPa})$ and tensile modulus (5.11 GPa) higher than neat PLA. PALF has a lower diameter and matrix get more surface area to attached with fibres and gives better interfacial bonding, though untreated composites did not show better result due to the presence of some waxy content on fibre surfaces. PALF showed higher cellulosic content which has a reason for better mechanical properties. From the obtained results, researchers observed similar trends with our results; they reported enhanced tensile strength of hybrid composites due to surface modification of coir pith. Treatment of fibres with $\mathrm{NaOH}$ on Kenaf/coir based PP hybrid composites display enhanced fibre/matrix bonding that leads to improvements in tensile strength and modulus of hybrid composites [33].

It is assumed that untreated PALF had very poor compatibility with PLA, a high amount of PALF in the composite is agglomerated, poor wettability can cause poor mechanical properties. After treatment, PALF enhanced the property of hybrid composites and showed that tensile properties increase with an increasing amount of PALF.

\subsection{SEM analysis}

The microstructure of fractured part of tensile tested samples of untreated and alkali-treated hybrid composites having various fibre loadings are illustrated in Figure 2. Figure 2a, 2c and 2e showed SEM images of the untreated hybrid composites whereas SEM micrographs of the treated sample of hybrid composites are presented in Figure 2b, 2d and 2f. It is evident from Figure 2a that fibres were uniformly distributed throughout in the C7P3 hybrid composites, void contents and micro-cracks were also illustrated on the matrix surface along with some fibre pullout. The fibre pullout showed that the bonding between fibre and matrix is weak and cracks on the matrix surface showed that either fibre loading is not enough or fibre distribution in the composite is heterogeneous [34]. Figure $2 b$ illustrated that the distribution of fibres found better and the fibre breakage is found more than fibre pullout which showed treatment improved the interfacial bonding than untreated C7P3.

A research done by Shih et al. [35] revealed that alkali-treated PALF improved bonding with a polymer. Some hybrid composites showed poor fibre distributions and fibres pull out. Moreover, Figure $2 \mathrm{c}$ revealed the clear matrix's surface has high void content (C1P1 hybrid composites), whereas Figure $2 d$ illustrated better fibre distribution, more broken fibre and less fibre pull-out. No micro-cracks observed, revealing better bonding between fibres and the polymer, thus provide better mechanical properties to hybrid composites [36]. In untreated C3P7, found micro-cracks and very clear fibre pullout. The fibre slippage of fibre and polymer can be seen in Figure 2e. Treated C3P7 showed comparatively better fibre distribution, interfacial strength, no void contents and micro-cracks, as observed from Figure 2f. Furthermore, composites fractured surface also showed lower fibre pull out that 


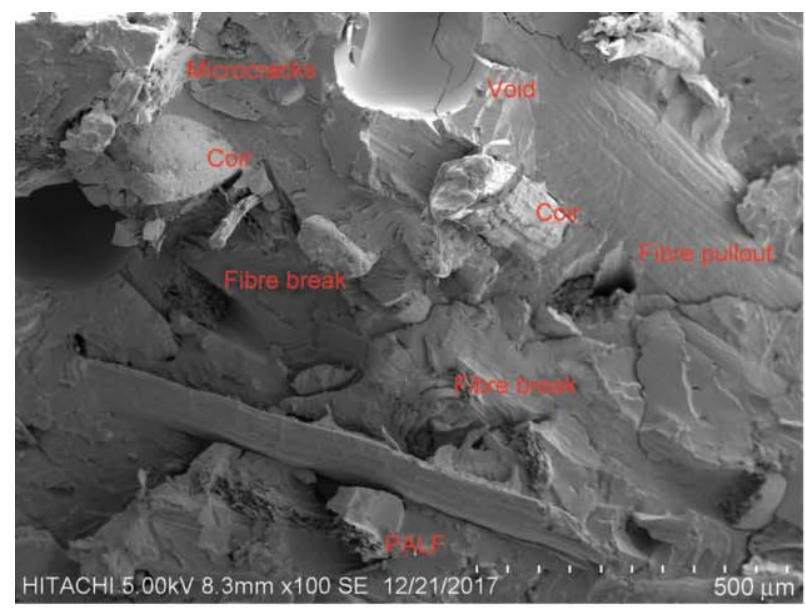

a)

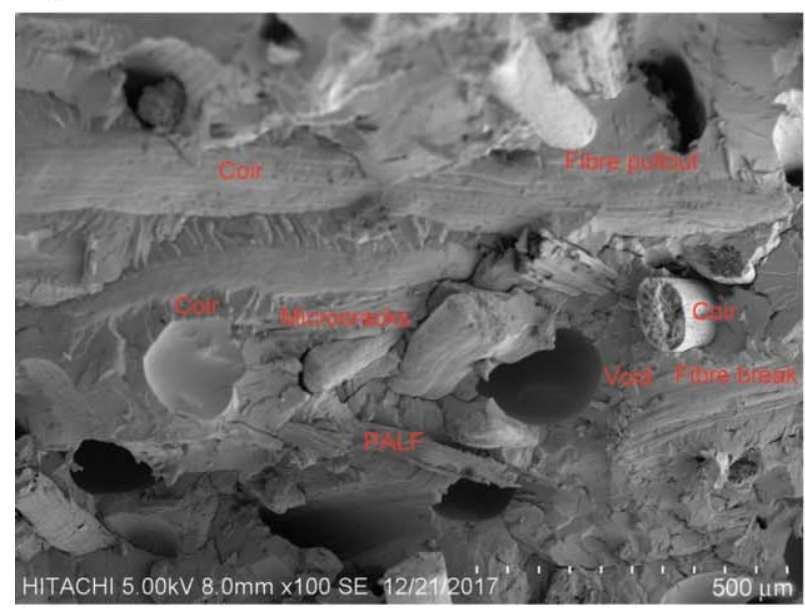

c)

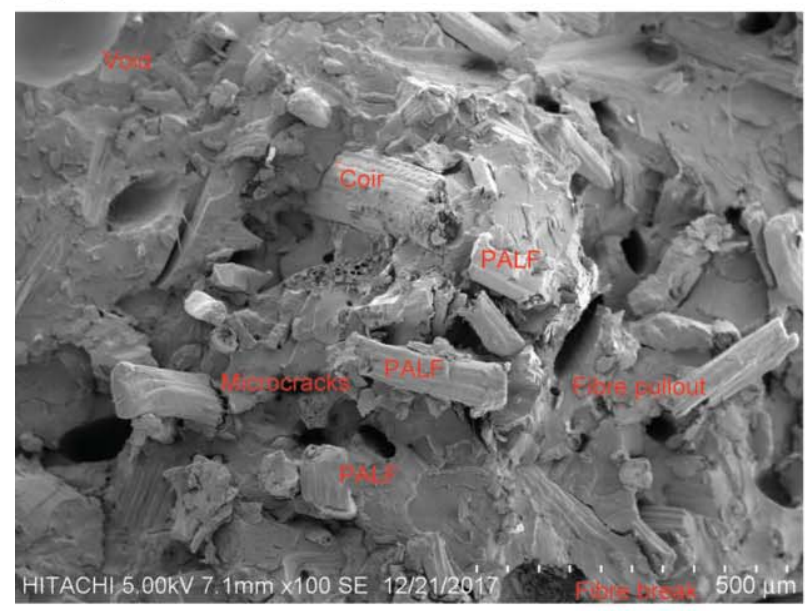

e)

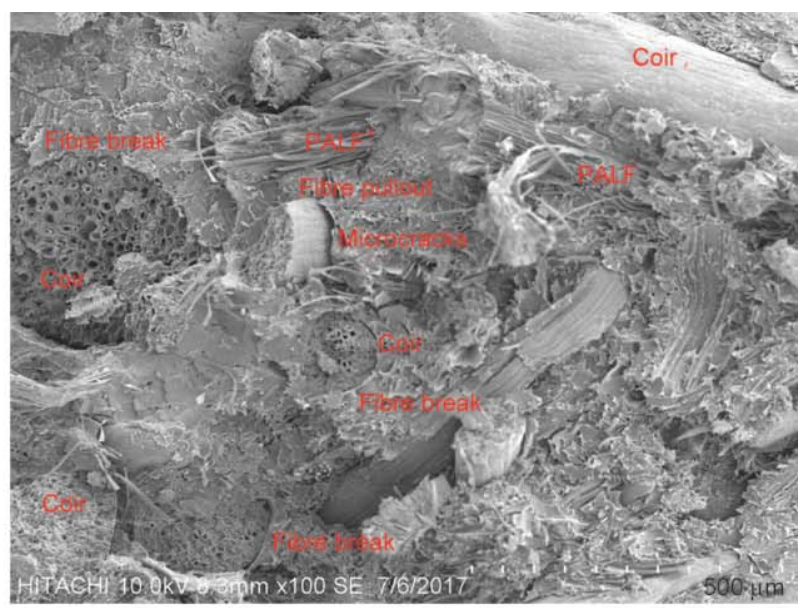

b)

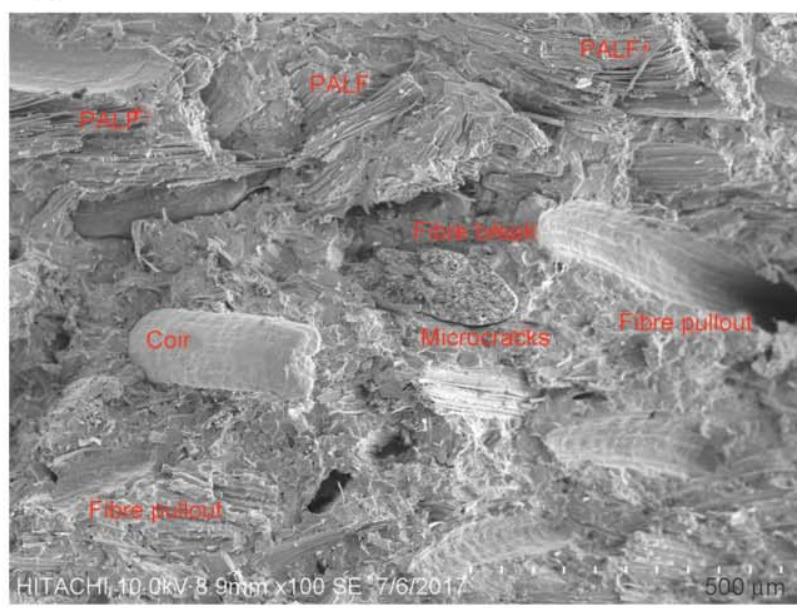

d)

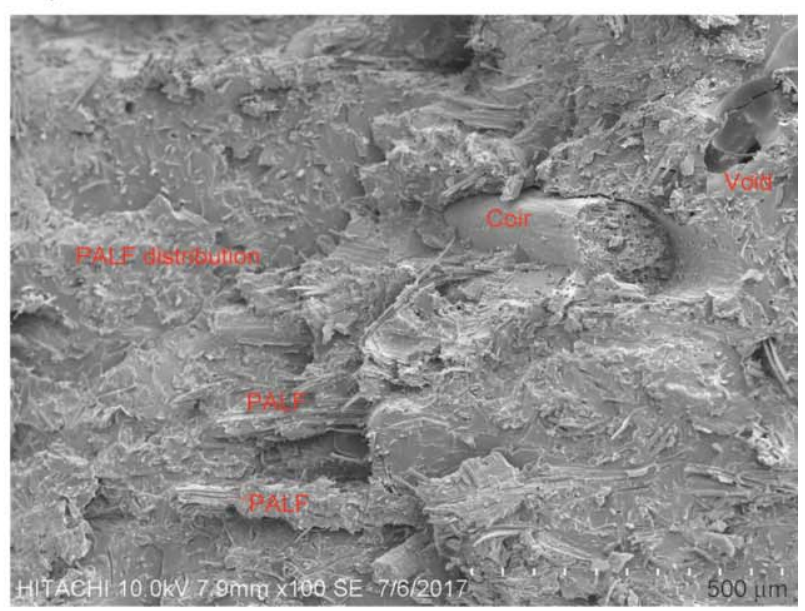

Figure 2. SEM images of tensile fractured CF/PALF/PLA hybrid composites; (a) untreated C7P3 (b) treated C7P3 (c) untreated C1P1 (d) treated C1P1 (e) untreated C3P7 and (f) treated C3P7.

causes fibres fracture, although in certain places fibre breakage are observed with no debonding, resulting polymer transferred effective stress to the fibres that ultimately improved the mechanical strength [34]. It can be ascribed by the fact that fibre treatments clean the surfaces and create rough surface and also increase the surface area, sometimes fibres are in bundle form, so treatments break the bundles and change the increase aspect ratio of the fibre; which then improved the adhesion with polymer matrices thus enhance the mechanical strength [37].

\subsection{FTIR of CF/PALF/PLA hybrid composites}

FTIR spectroscopy revealed the structural properties of CF/PALF/PLA hybrid composites and effects of 
alkali treatments on fibres in composites as shown in Figure 3. A broad band ranging from 3000 to $3700 \mathrm{~cm}^{-1}$ showed hydroxyl group $(-\mathrm{OH})$ in the cellulosic structure of fibres [31] that can be easily pointed out in every natural fibre reinforced hybrid composite, whereas band from $2800-3000 \mathrm{~cm}^{-1}$ revealed the presence of $\mathrm{C}-\mathrm{H}$ bond of methylene groups [38]. The treated hybrid composites (C7P3A, $\mathrm{C} 1 \mathrm{P} 1 \mathrm{~A}$ and $\mathrm{C} 3 \mathrm{P} 7 \mathrm{~A}$ in Figure 3) showed weak intensity between 3000 to $3700 \mathrm{~cm}^{-1}$ and $2800-3000 \mathrm{~cm}^{-1}$ that showed the less hydrophilic property and removal of cellulose and hemicelluloses. Alkaline treatments induced variation in the physicochemical properties of CF and PALF. This phenomenon has been associated with the mercerization of natural fibres. Mercerization removes waxy epidermal tissue, adhesive pectins and hemicelluloses that bind fibre bundles to each other and the pectin and hemicellulose-rich sheaths of the core $[39,40]$. Untreated hybrid composites showed a sharp peak at $2000 \mathrm{~cm}^{-1}$ while treated hybrid biocomposites are revealed near to disappeared peak spectrum. The peak at $2000 \mathrm{~cm}^{-1}$ was attributed to silicon compound. A sharp peak at $1736 \mathrm{~cm}^{-1}$ was attributed to $\mathrm{C}=\mathrm{O}$ stretching of carbonyl groups in both untreated and treated hybrid composites, showed availability of carbonyl groups evident the presence of hemicelluloses in fibres. Peaks at $1436 \mathrm{~cm}^{-1}$ indicated the presence of lignin structure in untreated hybrid composites but after treatment, these peaks showed weak intensity in all treated hybrid composites, it showed $\mathrm{NaOH}$ partially dissolved low molecular compounds from fibres [41]. All treated CF/PALF/PLA hybrid composites showed partially removed hemicelluloses and lignin. Many researchers [28, 40, 42, 43] reported the effect

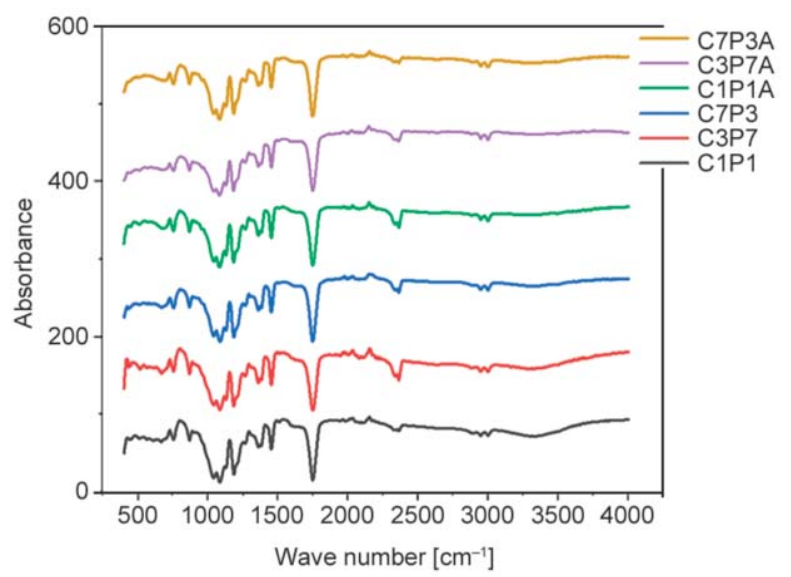

Figure 3. FTIR of untreated and treated CF/PALF/PLA hybrid composites.

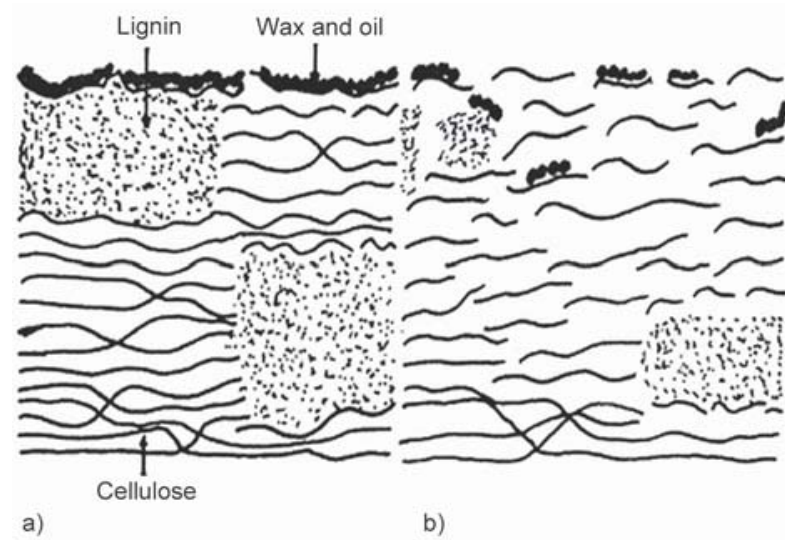

Figure 4. Typical structure of (a) untreated and (b) alkalized cellulosic fibre [44].

of alkali treatment on reducing moisture absorption of natural fibres polymer composites. The surface of the fibres gets cleaned during the surface treatments to eliminate impurities, lignin, oils and waxy substances (Figure 4a) which increases the fibre surface roughness (Figure $4 b$ ) and reducing the moisture absorption by removal of the coat of $\mathrm{OH}$ groups of fibres [44]. The proposed reaction mechanism of $\mathrm{NaOH}$ and $\mathrm{CF} / \mathrm{PALF}$ during treatment is given in Equation (3).

$$
\begin{aligned}
& \mathrm{CF} / \mathrm{PLAF}-\mathrm{OH}+\mathrm{NaOH} \longrightarrow \\
& \longrightarrow\left(\mathrm{CF} / \mathrm{PLAF}-\mathrm{O}^{-}\right) \mathrm{Na}^{+}+\mathrm{H}_{2} \mathrm{O}
\end{aligned}
$$

It is assumed that the strength of fibres will remain and interfacial bonding with polymer will improve and it will enhance the mechanical properties of hybrid composites [31].

\subsection{Impact properties}

Impact strength is defined as a measure of the fracture toughness of materials when applying an impact load. It is highly influenced by the material's nature which straightforwardly related to its toughness as a whole. It is the medium of cracks formation as well as the transformation of stress [45]. So, the impact strength of hybrid composites heavily depends on the structure and geometry of the natural fibre and fibre/matrix bonding. Izod notched impact strength of all tested composites are shown in Figure 5. A previous study [30] showed impact strength of neat PLA and Coir/PLA and PALF/PLA composite and found out that impact strength of neat PLA, Coir/PLA and PALF/PLA composites are $3.44,3.75$ and $3.57 \mathrm{~kJ} / \mathrm{m}^{2}$. The impact strength of both untreated and alkalitreated CF/PALF/PLA hybrid composites improved 


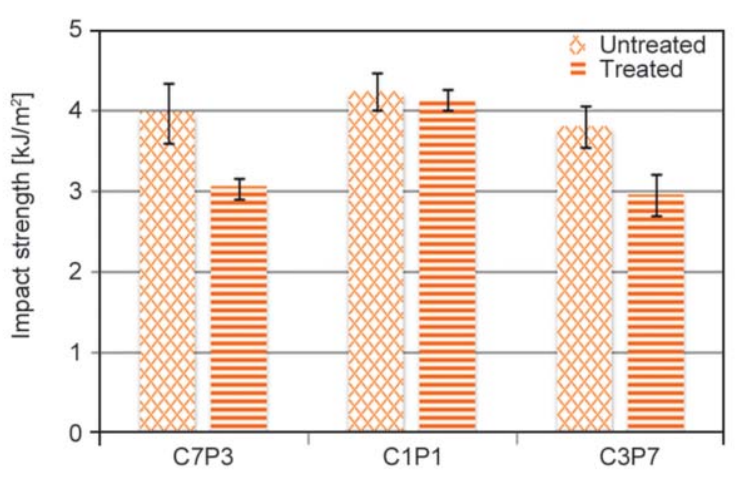

Figure 5. Impact strength of untreated and treated CF/PALF/PLA hybrid composites.

by the addition of CF. From Figure 5, it can be seen that treated C1P1 hybrid composites illustrates highest impact strength among all untreated and treated hybrid composites. A general trend of increase in impact strength is observed with the incorporation of CF. This could be due to CF's shallow structure which absorbs shock. In general, mechanical strength of natural fibres mainly depends on cellulosic constituents. Research study reviewed that PALF cellulosic structure ensures excellent elasticity that makes it high strain resistant when compared with similar fibres $[28,46]$.

In general, the toughness of fibre reinforced polymer composites depends on three major factors; i) the nature of the reinforcing fibre; ii) the polymer matrix and iii) their interfacial shear strength (IFSS) [47]. As can be seen in Figure 5, the hybrid composites containing $\mathrm{CF}$ and PALF in an equal ratio (1:1) have best impact strength and untreated hybrid composites showed slightly better impact strength compares to their successive alkali treated ones. This could be due to the delignification and partial dissolution of hemicelluloses in fibres by alkali treatment [31,39]. As per our results, it appears an adequate mix of CF's and PALF's provides effective resistance to fracture propagation during the impact tests. This is due to an enhancement in interfacial adhesion owing to homogeneity and stress capacity, which is associated with load distribution and fibre pull-out [48].

\subsection{Thermal stability}

Thermographs of untreated and alkali-treated CF/ PALF/PLA hybrid composites showed a single step thermal degradation in Figure 6. The initial weight loss occurred below $100^{\circ} \mathrm{C}$ temperature due to the evaporation or drying out of water molecules from the composites [28]. From the TGA results, thermal degradability of untreated hybrid composites (C3P7,

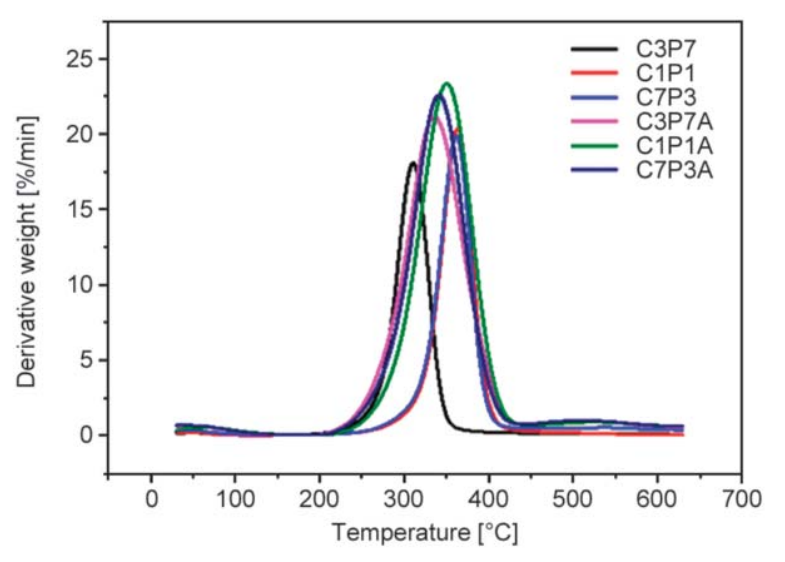

Figure 6. TGA plots of untreated and treated CF/PALF/PLA hybrid composites.

C1P1 and C7P3 were $92.96,89.65$ and $96.18 \%$ at $275.86,288.26$ and $284.56^{\circ} \mathrm{C}$ respectively. On the other hand, alkali-treated hybrid composites (C3P7A, C1P1A and C7P3A) increase the weight loss temperatures were also declined improved as compared to the untreated hybrid composites which can be seen in Table 4.

A previous study [29] showed thermal degradation of neat PLA and Coir/PLA and PALF/PLA composite and found out that $T_{\mathrm{g}}$ and ash content of neat PLA were $277.18^{\circ} \mathrm{C}$ and $1.05 \% . T_{\mathrm{g}}$ and ash content of Coir/PLA and PALF/PLA composites are $252.73^{\circ} \mathrm{C}$ and $11.17 \%$ and $287.23^{\circ} \mathrm{C}$ and $5.53 \%$.

The main weight loss took place in this phase were between 87 and $97 \%$ in the temperature range of $275-289^{\circ} \mathrm{C}$. The thermal degradation in this range is due to the breakdown of hemicelluloses, lignins, pectins plus the glycosidic linkages of cellulose of natural fibres via heat decomposition [32, 49]. In treated hybrid composites, the weight loss increased and the temperature is decreased, which may be due to the partial elimination of lignin and hemicelluloses. As reported in the literature [13] alkali treatments partially dissolved lignin and hemicelluloses of the fibre, that leads to an increase in the amount of exposed cellulose, ultimately change the crystallinity of CF. Lignin is also considered a thermal resistant component in natural fibres [50]

Researchers declared that alkali treatment partially dissolved binding material through the rupture of ester linkages between lignin and polyuronic, which increase the crystallinity index in alkali-treated fibres $[31,51,52]$. Moreover, the curve of treated fibres did not show higher temperature as a significant content of hemicelluloses being dissolved during alkali treatment. The final residues of untreated and treated 
Table 4. various percentage of thermal degradation of untreated and treated CF/PALF/PLA hybrid composites.

\begin{tabular}{|c|c|c|c|c|c|c|}
\hline \multirow{2}{*}{$\begin{array}{c}\text { Hybrid } \\
\text { composites }\end{array}$} & \multicolumn{3}{|c|}{$\begin{array}{l}\text { Temperature at thermal degradation, } T_{\mathrm{d}} \\
\qquad\left[{ }^{\circ} \mathrm{C}\right]\end{array}$} & \multicolumn{2}{|c|}{ Glass transition } & \multirow{2}{*}{$\begin{array}{c}\text { Final residue } \\
{[\%]}\end{array}$} \\
\hline & $T_{\mathrm{d} 10 \%}$ & $T_{\mathrm{d} 50 \%}$ & $T_{\mathrm{d} 90 \%}$ & $\begin{array}{c}\text { Temperature } \\
{\left[{ }^{\circ} \mathrm{C}\right]}\end{array}$ & $\begin{array}{l}\text { Weight loss } \\
{[\%]}\end{array}$ & \\
\hline C3P7 & 275 & 310 & 349 & 275.86 & 2.96 & 3.84 \\
\hline C1P1 & 269 & 304 & 470 & 288.26 & 89.65 & 6.55 \\
\hline C7P3 & 270 & 305 & 445 & 284.59 & 96.18 & 2.61 \\
\hline C3P7A & 268 & 318 & 393 & 279.35 & 88.23 & 2.53 \\
\hline C1P1A & 277 & 324 & 390 & 282.11 & 89.14 & 2.58 \\
\hline C7P3A & 267 & 320 & 407 & 279.35 & 87.36 & 2.54 \\
\hline
\end{tabular}

$\mathrm{CF} / \mathrm{PALF}$ hybrid composites at $600^{\circ} \mathrm{C}$ were $2-7 \%$. Remarkably, the highest final residue was found in C1P1 while low residues were 2.53 and 2.54 in C3P7A and C7P3A, respectively. All samples had similar residue content except $\mathrm{C} 1 \mathrm{P} 1$ and the amount of char residue in hybrid composites determine the flame retardancy behavior [28]. Overall we observed that PLA is not thermally stable biopolymer which we reported in our previous study [29] but fibre reinforcements and hybridization showed positive results. Coir fibre has higher lignin content which improved thermal properties and it can be seen higher coir content composites showed higher glass transition.

\subsection{Derivative thermogravimetry (DTG)}

Figure 7 illustrates the DTG plots of all untreated and treated CF/PALF/PLA hybrid composites. The degradation temperature is indicated by each peak in the given plots. As can be seen, single peaks were present in the range of $250-420^{\circ} \mathrm{C}$. An initial peak was also observed below $100^{\circ} \mathrm{C}$ attaining its maximum rate of $1.1 \% / \mathrm{min}$, which proves the existence of hydroxyl group in natural fibres [37]. The main peaks were also obvious in Figure 5, which illustrates maximum weight losses by degradation. The

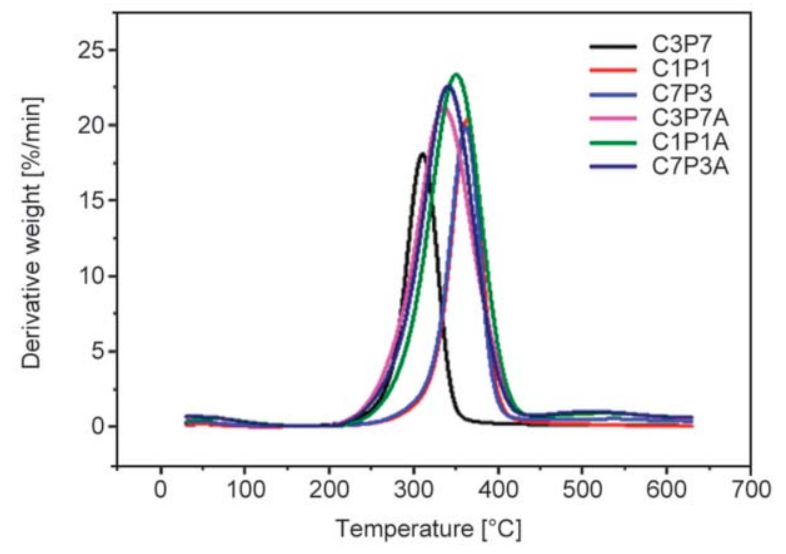

Figure 7. DTG plots of untreated and treated CF/PALF/PLA hybrid composites. decomposition peaks of treated hybrid composites shifted towards lower temperatures except for C3P7A. C3P7A C7P3A hybrid composites showed $21 \% / \mathrm{min}$ rate of degradation of derivative weights whereas $\mathrm{C} 1 \mathrm{P} 1 \mathrm{~A}$ and $\mathrm{C} 7 \mathrm{P} 3 \mathrm{~A}$ hybrid composites showed 24 and $23 \% / \mathrm{min}$ rates of degradation of derivative weights respectively. On the other hand, untreated hybrid composites revealed a low rate of weight loss. Degradation rate indicated the breakdown of cellulose and hemicelluloses constituents of the fibres as well as the presence of voids or loose fibres in the composites under examination [53].

\subsection{Thermomechanical analysis (TMA)}

TMA was conducted to assess the coefficient of thermal expansion (CTE) of material. Assessment of CTE was carried out in both the rubbery and glassy regions of the samples. The CTE of the materials were measured before and after the glass transition $\left(T_{\mathrm{g}}\right)$ in the linear trends of the thermograms. Figure 8 illustrates the TMA graphs of all the studied composites. Treated and untreated $\mathrm{C} 1 \mathrm{P} 1$ and $\mathrm{C} 3 \mathrm{P} 7$ hybrid composites revealed steep down curve towards the rubbery stage which is associated with low crosslinking materials [54]. Moreover, treated hybrid

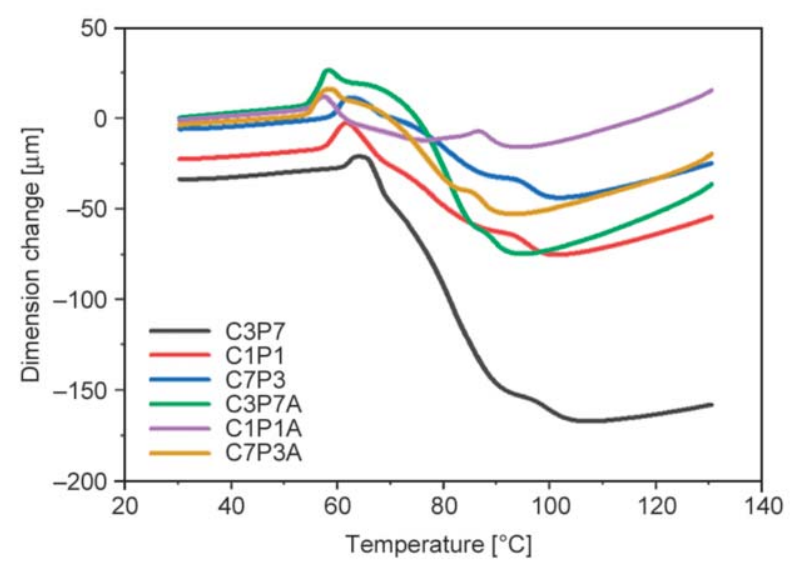

Figure 8. CTE of untreated and treated CF/PALF/PLA hybrid composites. 
composites displayed $T_{\mathrm{g}}$ at below $60^{\circ} \mathrm{C}$ but untreated hybrid displayed $T_{\mathrm{g}}$ at above $60^{\circ} \mathrm{C}$, even though the difference is very low. The CTEof treated hybrid composites displayed the least values than untreated hybrid composites. The lowest decrease for both glassy and rubbery regions showed for $\mathrm{C} 1 \mathrm{P} 1 \mathrm{~A}$, followed by C7P3A. The lower $T_{\mathrm{g}}$ in treated hybrid composites could be due to the removal of lignin, while in the rubbery stage, hybrid composites showed dimension change dramatically because of the matrix properties.

\subsection{Water absorption $(W A)$}

$W A$ tests were performed for both alkali-treated and untreated CF/PALF/PLA hybrid composites for certain periods of time, i.e, 3, 5 and 7 days. As the developed composites made up of natural fibres which usually absorb water due to numerous reasons such as cellulose, hemicelluloses content, humidity, the hydrophilicity of fibres, presence of voids, temperature and viscosity of matrix [55]. As displayed in Figure 9, the untreated hybrid composites revealed more $W A$ compared to treated hybrid composites. Out of all the untreated hybrid composites, C7P3 absorbed the least water followed by $\mathrm{C} 1 \mathrm{P} 1$ however C3P7 displayed highest $W A$ in seven days (7.36\%). This high $W A$ implies the presence of voids and porosity in untreated composites, furthermore, the weight of composite also get increases by trapping water inside these voids [55]. The difference of theoretical densities and measured densities showed in Table 3 that samples have some trapped void areas.

Alkali treated hybrid composites showed lower $W A$ compared to untreated hybrid and the lowest $W A$ was found in C7P3A with 5.24\% calculated value. C1P1A absorbed the highest amount of water among the

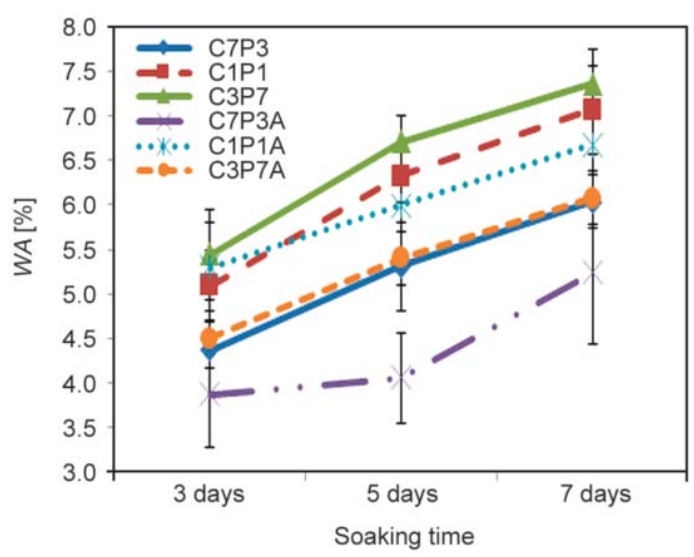

Figure 9. WA of untreated and treated CF/PALF/PLA hybrid composites. treated composites. Findings also suggest that the hydroxyl groups were removed by alkali treatment resulting in treated hybrid to absorbed lesser water. Interestingly, fibre treatments usually fill the surface's pores and create a barrier for a water molecule to enter into fibres [56]. Theoretically, C3P7A supposed to have higher $W A$ owing to higher PALF content and C7P3A should reveal lower WA. However, the results revealed that $\mathrm{C} 1 \mathrm{P} 1 \mathrm{~A}$ absorb more water. In many studies, it is reported that the presence of hydroxyl groups in natural fibres offers a gateway to water molecules into the composites. Besides this pore fraction, void content, lumen size and fibre-matrix adhesion also contribute to $W A[57,58]$. The long-time immersion of composites into the water leads to absorption of water molecules through capillary action. This absorbed water fills the voids and cracks/pores in the composites [59,60]. Overall based on the perfect fibres matrix adhesion with no microcracks and voids on the surface area of matrix treated hybrid composites have better adhesive properties and lower $W A$.

\subsection{Thickness swelling (TS)}

Dimensional stability is best investigated by analysing the moisture-resistant capacity of the composites through TS measurements. Samples were soaked into the water to investigate dimension stability. Generally, most of the natural fibres behave by means of capillary action when soaked into the water which caused the intake of water into the sample ultimately leads to the swelling of fibres and thus increase the sample's dimension [55]. From Figure 10, the treated hybrid composites displayed higher water-resistant, however, untreated hybrid composites revealed higher TS and vice versa. Among all the samples tested, C1P1A revealed highest dimensional stability (DS) while untreated C3P7 showed least at nearly $10 \%$. Amongst the treated hybrid composites, C3P7A and C7P3A displayed similar low DS while C1P1 illustrates the least TS among untreated hybrid composites.

The presence of void and high porosity is the major cause of high TS in the untreated hybrid composites. Moreover, the dimension of lignocellulosic based composites is based on the water content in the lumen, predominantly in the thickness and the linear expansion caused by reversible and irreversible swelling of the composites [61]. PALF contains a higher amount of cellulosic content [31] and C3P7 hybrid 


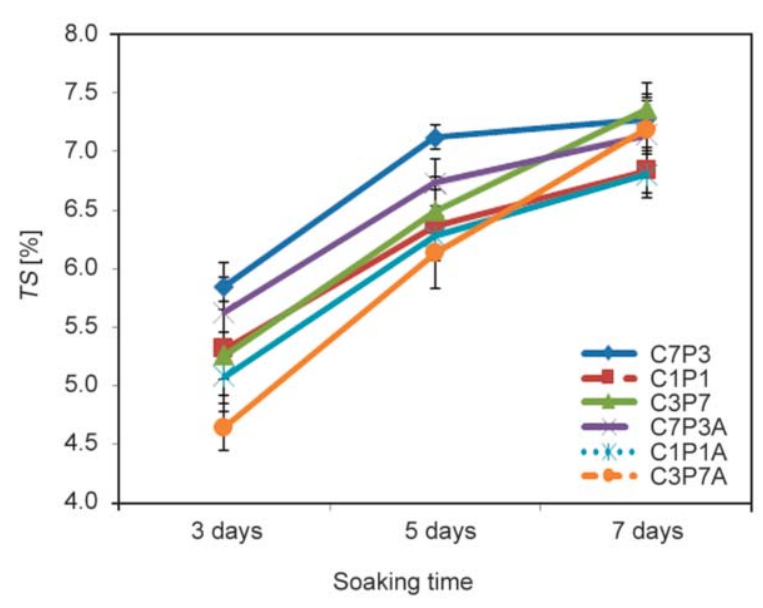

Figure 10. TS of untreated and treated CF/PALF/PLA hybrid composites.

composites have higher PALF loading, which may attribute towards high TS. Alternatively, treated hybrid composites have less $T S$ thus possessed higher DS. It can be assumed that alkali-treated composites had lesser pores exposed to water and voids content, as the surface treatment removed the $-\mathrm{OH}$ groups from the fibres surface which resulted in improved interfacial bonds.

\section{Conclusions}

The current study presents an effort to improve the mechanical, morphological, thermal and physical properties of PLA composites through hybridization with different fibre portioning of alkali-treated $\mathrm{CF}$ and PALF. The tensile test showed that among the untreated and treated hybrid composites, treated C3P7 hybrid showed the highest tensile strength and modulus. Interestingly, the highest PALF portion in hybrid composites revealed remarkable improvement in the tensile properties. However, untreated C1P1 hybrid composites revealed the highest impact strength compared to its treated counterpart among all hybrid composites. High impact strength of untreated C1P1can be ascribed to a higher content of PALF having high cellulosic content influencing its mechanical strength and ultimately to the composites. The TGA curve showed less thermal stability in treated composites as a considerable amount of hemicelluloses and lignin removed during the alkali treatment. The final char residues of untreated and treated CF/PALF hybrid composites at $600{ }^{\circ} \mathrm{C}$ were $2-7 \%$. Treatment also affects the $T_{\mathrm{g}}$ although the difference is very low and the CTE value of hybrid composites. The CTE of treated hybrid composites displayed the least values than untreated. Remarkably alkali treatment also reduces the $W A$ tendencies compared to untreated. C7P3 hybrid composites absorbed least moisture and C7P3A showed least WA among untreated and treated composites. WA and TS test illustrate that less PALF content reduced the WA tendencies and void content. Overall, we concluded that among all hybrid composites, $\mathrm{C} 1 \mathrm{P} 1 \mathrm{~A}$ revealed the highest stability dimensionally while untreated C3P7 hybrid composites showed at least nearly $10 \%$.

\section{Acknowledgements}

This work is funded by Researchers Supporting Project number(RSP-2019/117), King Saud University, Riyadh, Saudi Arabia. This research was partly funded by King Mongkut's University of Technology North Bangkok through the PostDoc Program KMUTNB-Post-62-03.

\section{References}

[1] Dicker M. P. M., Duckworth P. F., Baker A. B., Francois G., Hazzard M. K., Weaver P. M.: Green composites: A review of material attributes and complementary applications. Composites Part A: Applied Science and Manufacturing, 56, 280-289 (2014).

https://doi.org/10.1016/j.compositesa.2013.10.014

[2] Nasir M., Khali D. P., Jawaid M., Tahir P. M., Siakeng R., Asim M., Khan T. A.: Recent development in binderless fiber-board fabrication from agricultural residues: A review. Construction and Building Materials, 211, 502-516 (2019). https://doi.org/10.1016/j.conbuildmat.2019.03.279

[3] Siakeng R., Jawaid M., Ariffin H., Salit M. S.: Effects of surface treatments on tensile, thermal and fibre-matrix bond strength of coir and pineapple leaf fibres with poly lactic acid. Journal of Bionic Engineering, 15, 1035-1046 (2018). https://doi.org/10.1007/s42235-018-0091-z

[4] Rahman M. M., Khan M. A.: Surface treatment of coir (Cocos nucifera) fibers and its influence on the fibers' physico-mechanical properties. Composites Science and Technology, 67, 2369-2376 (2007).

https://doi.org/10.1016/j.compscitech.2007.01.009

[5] Gregorova A., Hrabalova M., Kovalcik R., Wimmer R.: Surface modification of spruce wood flour and effects on the dynamic fragility of PLA/wood composites. Polymer Engineering and Science, 51, 143-150 (2011). https://doi.org/10.1002/pen.21799

[6] Dong Y., Ghataura A., Takagi H., Haroosh H. J., Nakagaito A. N., Lau K-T.: Polylactic acid (PLA) biocomposites reinforced with coir fibres: Evaluation of mechanical performance and multifunctional properties. Composites Part A: Applied Science and Manufacturing, 63, 76-84 (2014). https://doi.org/10.1016/j.compositesa.2014.04.003 
[7] Asim M., Abdan K., Jawaid M., Nasir M., Dashtizadeh Z., Ishak M., Hoque M. E.: A review on pineapple leaves fibre and its composites. International Journal of Polymer Science, 2015, 950567/1-950567/16 (2015).

https://doi.org/10.1155/2015/950567

[8] Le Troedec M., Sedan D., Peyratout C., Bonnet J. P., Smith A., Guinebretiere R., Gloaguen V., Krausz P.: Influence of various chemical treatments on the composition and structure of hemp fibres. Composites Part A: Applied Science and Manufacturing, 39, 514-522 (2008).

https://doi.org/10.1016/j.compositesa.2007.12.001

[9] Petchwattana N., Covavisaruch S.: Mechanical and morphological properties of wood plastic biocomposites prepared from toughened poly(lactic acid) and rubber wood sawdust (Hevea brasiliensis). Journal of Bionic Engineering, 11, 630-637 (2014).

https://doi.org/10.1016/S1672-6529(14)60074-3

[10] Arrakhiz F. Z., Elachaby M., Bouhfid R., Vaudreuil S., Essassi M., Qaiss A.: Mechanical and thermal properties of polypropylene reinforced with alfa fiber under different chemical treatment. Materials and Design, 35, 318-322 (2012).

https://doi.org/10.1016/j.matdes.2011.09.023

[11] Han S. O., Karevan M., Sim I. N., Bhuiyan M. A., Jang Y. H., Ghaffar J., Kalaitzidou K.: Understanding the reinforcing mechanisms in kenaf fiber/PLA and kenaf fiber/pp composites: A comparative study. International Journal of Polymer Science, 2012, 679252/1-679252/8 (2012).

https://doi.org/10.1155/2012/679252

[12] Bozaci E., Sever K., Sarikanat M., Seki Y., Demir A., Ozdogan E., Tavman I.: Effects of the atmospheric plasma treatments on surface and mechanical properties of flax fiber and adhesion between fiber-matrix for composite materials. Composites Part B: Engineering, 45, 565-572 (2013).

https://doi.org/10.1016/j.compositesb.2012.09.042

[13] Rosa M. F., Chiou B-S., Medeiros E. S., Wood D. F., Mattoso L. H. C., Orts W. J., Imam S. H.: Biodegradable composites based on starch/evoh/glycerol blends and coconut fibers. Journal of Applied Polymer Science, 111, 612-618 (2009).

https://doi.org/10.1002/app.29062

[14] Kaewpirom S., Worrarat C.: Preparation and properties of pineapple leaf fiber reinforced poly(lactic acid) green composites. Fibers and Polymers, 15, 1469-1477 (2014). https://doi.org/10.1007/s12221-014-1469-0

[15] Li Y., Pickering K. L.: Hemp fibre reinforced composites using chelator and enzyme treatments. Composites Science and Technology, 68, 3293-3298 (2008). https://doi.org/10.1016/j.compscitech.2008.08.022

[16] Gustavsson M. T., Persson P. V., Iversen T., Martinelle M., Hult K., Teeri T. T., Brumer H.: Modification of cellulose fiber surfaces by use of a lipase and a xyloglucan endotransglycosylase. Biomacromolecules, 6, 196-203 (2005).

https://doi.org/10.1021/bm049588i
[17] Xie Y., Hill C. A. S., Xiao Z., Militz H., Mai C.: Silane coupling agents used for natural fiber/polymer composites: A review. Composites Part A: Applied Science and Manufacturing, 41, 806-819 (2010). https://doi.org/10.1016/j.compositesa.2010.03.005

[18] Sawpan M. A., Pickering K. L., Fernyhough A.: Effect of various chemical treatments on the fibre structure and tensile properties of industrial hemp fibres. Composites Part A: Applied Science and Manufacturing, 42, 888895 (2011). https://doi.org/10.1016/j.compositesa.2011.03.008

[19] Vasile C., Râpă M., Ştefan M., Stan M., Macavei S., Darie-Niţă R., Barbu-Tudoran L., Vodnar D., Popa E., Ştefan R., Borodi G., Berbu M.: New PLA/ZnO: Cu/Ag bionanocomposites for food packaging. Express Polymer Letters, 11, 531-544 (2017).

https://doi.org/10.3144/expresspolymlett.2017.51

[20] Siakeng R., Jawaid M., Ariffin H., Sapuan S., Asim M., Saba N.: Natural fiber reinforced polylactic acid composites: A review. Polymer Composites, 40, 446-463 (2019) https://doi.org/10.1002/pc.24747

[21] Asim M., Jawaid M., Abdan K., Ishak M. R., Alothman O. Y.: Effect of hybridization on the mechanical properties of pineapple leaf fiber/kenaf phenolic hybrid composites. Journal of Renewable Materials, 5, 3-4 (2017). https://doi.org/10.7569/JRM.2017.634148

[22] Asim M., Jawaid M., Paridah M. T., Saba N., Nasir M., Shahroze R. M.: Dynamic and thermo-mechanical properties of hybridized kenaf/PALF reinforced phenolic composites. Polymer Composites, 40, 3814-3822 (2019). https://doi.org/10.1002/pc.25240

[23] Asim M., Jawaid M., Abdan K., Ishak M.: The effect of silane treated fibre loading on mechanical properties of pineapple leaf/kenaf fibre filler phenolic composites. Journal of Polymers and the Environment, 26, 15201527 (2018). https://doi.org/10.1007/s10924-017-1060-z

[24] Siakeng R., Jawaid M., Ariffin H., Sapuan S. M.: Physical properties of coir and pineapple leaf fibre reinforced polylactic acid hybrid composites. IOP Conference Series: Materials Science and Engineering, 290, 012031/1-012031/7 (2018). https://doi.org/10.1088/1757-899X/290/1/012031

[25] Pickering K. L., Efendy M. G. A.: Preparation and mechanical properties of novel bio-composite made of dynamically sheet formed discontinuous harakeke and hemp fibre mat reinforced PLA composites for structural applications. Industrial Crops and Products, 84, 139-150 (2016).

https://doi.org/10.1016/j.indcrop.2016.02.005

[26] Duhovic M., Horbach S., Bhattacharyya D.: Improving the Interface strength in flax fibre poly(lactic) acid composites. Journal of Biobased Materials and Bioenergy, 3, 188-198 (2009). https://doi.org/10.1166/jbmb.2009.1017 
[27] Venkateshwaran N., Elayaperumal A., Sathiya G.: Prediction of tensile properties of hybrid-natural fiber composites. Composites Part B: Engineering, 43, 793-796 (2012).

https://doi.org/10.1016/j.compositesb.2011.08.023

[28] Asim M., Jawaid M., Abdan K., Nasir M.: Effect of alkali treatments on physical and mechanical strength of pineapple leaf fibres. IOP Conference Series: Materials Science and Engineering, 290, 012030/1-012030/7 (2018). https://doi.org/10.1088/1757-899X/290/1/012030

[29] Siakeng R., Jawaid M., Ariffin H., Sapuan S. M.: Thermal properties of coir and pineapple leaf fibre reinforced polylactic acid hybrid composites. IOP Conference Series: Materials Science and Engineering, 368, 012019/1012019/7 (2018).

https://doi.org/10.1088/1757-899X/368/1/012019

[30] Siakeng R., Jawaid M., Ariffin H., Sapuan S.: Mechanical, dynamic, and thermomechanical properties of coir/ pineapple leaf fiber reinforced polylactic acid hybrid biocomposites. Polymer Composites, 40, 2000-2011 (2019). https://doi.org/10.1002/pc.24978

[31] Asim M., Jawaid M., Abdan K., Ishak M. R.: Effect of alkali and silane treatments on mechanical and fibrematrix bond strength of kenaf and pineapple leaf fibres. Journal of Bionic Engineering, 13, 426-435 (2016). https://doi.org/10.1016/S1672-6529(16)60315-3

[32] Asim M., Jawaid M., Abdan K., Ishak M. R.: Effect of pineapple leaf fibre and kenaf fibre treatment on mechanical performance of phenolic hybrid composites. Fibers and Polymers, 18, 940-947 (2017). https://doi.org/10.1007/s12221-017-1236-0

[33] Islam M. S., Hasbullah N. A. B., Hasan M., Talib Z. A., Jawaid M., Haafiz M. M.: Physical, mechanical and biodegradable properties of kenaf/coir hybrid fiber reinforced polymer nanocomposites. Materials Today Communications, 4, 69-76 (2015).

https://doi.org/10.1016/j.mtcomm.2015.05.001

[34] Jawaid M., Khalil H. P. S. A., Hassan A., Dungani R., Hadiyane A.: Effect of jute fibre loading on tensile and dynamic mechanical properties of oil palm epoxy composites. Composites Part B: Engineering, 45, 619-624 (2013). https://doi.org/10.1016/j.compositesb.2012.04.068

[35] Shih Y-F., Chang W-C., Liu W-C., Lee C-C., Kuan C-S., Yu Y-H.: Pineapple leaf/recycled disposable chopstick hybrid fiber-reinforced biodegradable composites. Journal of the Taiwan Institute of Chemical Engineers, 45, 2039-2046 (2014). https://doi.org/10.1016/j.jtice.2014.02.015

[36] El Mechtali F. Z., Essabir H., Nekhlaoui S., Bensalah M. O., Jawaid M., Bouhfid R., Qaiss A.: Mechanical and thermal properties of polypropylene reinforced with almond shells particles: Impact of chemical treatments. Journal of Bionic Engineering, 12, $483-494$ (2015). https://doi.org/10.1016/S1672-6529(14)60139-6
[37] Ridzuan M. J. M., Majid M. S. A., Afendi M., Mazlee M. N., Gibson A. G.: Thermal behaviour and dynamic mechanical analysis of Pennisetum purpureum/glassreinforced epoxy hybrid composites. Composite Structures, 152, 850-859 (2016).

https://doi.org/10.1016/j.compstruct.2016.06.026

[38] Nasir M., Gupta A., Beg M. D. H., Chua G. K., Asim M.: Laccase application in medium density fibreboard to prepare a bio-composite. RSC Advances, 4, 1152011527 (2014).

https://doi.org/10.1039/C3RA40593A

[39] Herrera-Franco P. J., Valadez-Gonzalez A.: A study of the mechanical properties of short natural-fiber reinforced composites. Composites Part B: Engineering, 36, 597-608 (2005).

https://doi.org/10.1016/j.compositesb.2005.04.001

[40] Mohammed L., Ansari M. N. M., Pua G., Jawaid M., Islam M. S.: A review on natural fiber reinforced polymer composite and its applications. International Journal of Polymer Science, 2015, 243947/1-243947/15 (2015). https://doi.org/10.1155/2015/243947

[41] Lopattananon N., Panawarangkul K., Sahakaro K., Ellis B.: Performance of pineapple leaf fiber-natural rubber composites: The effect of fiber surface treatments. Journal of Applied Polymer Science, 102, 1974-1984 (2006). https://doi.org/10.1002/app.24584

[42] Ticoalu A., Aravinthan T., Cardona F.: A review of current development in natural fiber composites for structural and infrastructure applications. in 'Proceedings of the Southern Region Engineering Conference, Toowoomba, Australia' SREC2010-F1-5/1-SREC2010-F1-5/5 (2010).

[43] John M. J., Francis B., Varughese K. T., Thomas S.: Effect of chemical modification on properties of hybrid fiber biocomposites. Composites Part A: Applied Science and Manufacturing, 39, 352-363 (2008). https://doi.org/10.1016/j.compositesa.2007.10.002

[44] Mwaikambo L. Y., Ansell M. P.: Chemical modification of hemp, sisal, jute, and kapok fibers by alkalization. Journal of Applied Polymer Science, 84, 2222-2234 (2002).

https://doi.org/10.1002/app.10460

[45] Joseph S., Sreekala M. S., Oommen Z., Koshy P., Thomas S.: A comparison of the mechanical properties of phenol formaldehyde composites reinforced with banana fibres and glass fibres. Composites Science and Technology, 62, 1857-1868 (2002).

https://doi.org/10.1016/S0266-3538(02)00098-2

[46] Raquez J-M., Deléglise M., Lacrampe M-F., Krawczak P.: Thermosetting (bio)materials derived from renewable resources: A critical review. Progress in Polymer Science, 35, 487-509 (2010).

https://doi.org/10.1016/j.progpolymsci.2010.01.001 
[47] Huda M. S., Drzal L. T., Misra M., Mohanty A. K., Williams K., Mielewski D. F.: A study on biocomposites from recycled newspaper fiber and poly(lactic acid). Industrial and Engineering Chemistry Research, 44, 5593 5601 (2005). https://doi.org/10.1021/ie0488849

[48] Yu T., Ren J., Li S., Yuan H., Li Y.: Effect of fiber surface-treatments on the properties of poly(lactic acid)/ ramie composites. Composites Part A: Applied Science and Manufacturing, 41, 499-505 (2010).

https://doi.org/10.1016/j.compositesa.2009.12.006

[49] Bajpai P. K., Singh I., Madaan J.: Development and characterization of PLA-based green composites: A review. Journal of Thermoplastic Composite Materials, 27, 52-81 (2014).

https://doi.org/10.1177/0892705712439571

[50] Asim M., Jawaid M., Nasir M., Saba N.: Effect of fiber loadings and treatment on dynamic mechanical, thermal and flammability properties of pineapple leaf fiber and kenaf phenolic composites. Journal of Renewable Materials, 6, 383-393 (2018).

https://doi.org/10.7569/JRM.2017.634162

[51] Orue A., Jauregi A., Unsuain U., Labidi J., Eceiza A., Arbelaiz A.: The effect of alkaline and silane treatments on mechanical properties and breakage of sisal fibers and poly(lactic acid)/sisal fiber composites. Composites Part A: Applied Science and Manufacturing, 84, 186195 (2016).

https://doi.org/10.1016/j.compositesa.2016.01.021

[52] Krishnaiah P., Ratnam C. T., Manickam S.: Enhancements in crystallinity, thermal stability, tensile modulus and strength of sisal fibres and their PP composites induced by the synergistic effects of alkali and high intensity ultrasound (HIU) treatments. Ultrasonics Sonochemistry, 34, 729-742 (2017).

https://doi.org/10.1016/j.ultsonch.2016.07.008

[53] El-Shekeil Y. A., Sapuan S. A., Abdan K., Zainudin E. S.: Influence of fiber content on the mechanical and thermal properties of kenaf fiber reinforced thermoplastic polyurethane composites. Materials and Design, 40, 299-303 (2012).

https://doi.org/10.1016/j.matdes.2012.04.003
[54] Ju J. W., Lee H. W.: A micromechanical damage model for effective elastoplastic behavior of partially debonded ductile matrix composites. International Journal of Solids and Structures, 38, 6307-6332 (2001). https://doi.org/10.1016/S0020-7683(01)00124-X

[55] Jawaid M., Khalil H. P. S. A.: Cellulosic/synthetic fibre reinforced polymer hybrid composites: A review. Carbohydrate Polymers, 86, 1-18 (2011). https://doi.org/10.1016/j.carbpol.2011.04.043

[56] Akas, Girisha K. G., Gupta N. S. V., Rao K. V. S.: A study on flammability and moisture absorption behavior of sisal/coir fiber reinforced hybrid composites. IOP Conference Series: Materials Science and Engineering, 191, 012003/1-012003/5 (2017). https://doi.org/10.1088/1757-899X/191/1/012003

[57] Mariatti M., Jannah M., Bakar A. A., Khalil H. P. S. A.: Properties of banana and pandanus woven fabric reinforced unsaturated polyester composites. Journal of composite materials, 42, 931-941 (2008). https://doi.org/10.1177/0021998308090452

[58] Ashori A., Sheshmani S.: Hybrid composites made from recycled materials: Moisture absorption and thickness swelling behavior. Bioresource Technology, 101, 47174720 (2010).

https://doi.org/10.1016/j.biortech.2010.01.060

[59] Khalil H. P. S. A., Jawaid M., Bakar A. A.: Woven hybrid composites: Water absorption and thickness swelling behaviours. BioResources, 6, 1043-1052 (2011).

[60] Ahmed K. S., Vijayarangan S.: Experimental characterization of woven jute-fabric-reinforced isothalic polyester composites. Journal of Applied Polymer Science, 104, 2650-2662 (2007). https://doi.org/10.1002/app.25652

[61] Khalil H. P. S. A., Issam A. M., Shakri M. T. A., Suriani R., Awang A. Y.: Conventional agro-composites from chemically modified fibres. Industrial Crops and Products, 26, 315-323 (2007). https://doi.org/10.1016/j.indcrop.2007.03.010 